\title{
DUNE EROSION NEAR SEA WALLS: MODEL-DATA COMPARISON
}

\author{
Pieter van Geer ${ }^{1}$, Bram de Vries ${ }^{2}$, Ap van Dongeren ${ }^{1}$ and Jaap van Thiel de Vries ${ }^{1,2}$
}

\begin{abstract}
This paper describes the validation of the dune erosion model XBeach with laboratory measurement data of dune erosion in the presence of sea walls and revetments. Simulation results show that the essential dune set back processes are captured by the model and that the measurements at most locations are approximated quite well. Some aspects however need more attention in further research. The alongshore distance from a fixed structure over which the dune erosion is influenced was not well captured by the model. Also the absence of short wave run-up on the revetment still causes an underestimation of the amount of dune erosion above the revetment. Furthermore the influence of the angle of incidence was investigated with a conceptual model approach. This revealed a relatively high influence of the angle of incidence on the governing flow pattern in front of a transition between a dune and a fixed structure.
\end{abstract}

Keywords: dune erosion; dike; sea wall; XBeach; validation; laboratory experiments

\section{INTRODUCTION}

\section{Assessing dune safety near fixed structures}

This paper describes the validation of the XBeach (Roelvink et al., 2009) dune erosion model with laboratory measurement data of dune erosion in the presence of sea walls and revetments. Dutch water boards have to assess the safety of dunes at the North Sea Coast in The Netherlands against hinterland flooding every six years by law. They test whether these dunes have sufficient strength to withstand hydraulic loads to a normative probability of exceedance. For future assessments of dunes, new rules based on new knowledge of physical processes are currently being developed within the Rijkswaterstaat (Public Works Department) program "Strengths and Loads on Water Defenses (SBW)". An important research item of this program is the impact of unerodible structures such as seawalls and revetments on the erosion of nearby sandy dunes. For this purpose laboratory experiments have been carried out to study the influence of various types of fixed structures on dune erosion (Boers et al., 2011). The obtained dataset served to validate the storm impact model XBeach for these types of situations.

\section{Laboratory experiments}

Boers et al. (2011) describe the laboratory experiments that are used for validation of XBeach in this paper in detail. The experiments were conducted in a $25 \times 25$ section of Deltares' Delta basin which is equipped with a multidirectional second-order wave generator with Active Reflection Compensation. The physical model was constructed of sediment with a $\mathrm{D}_{50}$ of $125 \mu \mathrm{m}$ and concrete objects to represent the fixed structures. The experimental set-up included two configurations of a combination of dunes, dunes with a revetment, and seawalls. Figure 1 visualizes these two configurations. The first configuration included three breaches with various widths constructed between concrete elements. Configuration 2 contained a transition between a concrete element and an unprotected dune section as well as an artificial dune foot revetment with a breach in the middle. The dune foot revetment consisted of a lowered concrete element with sand on top (see also the picture in the figure).

Long crested irregular waves generated with wave maker with two different peak periods caused erosion of the dune front. This paper only discusses the results of the comparison between XBeach and the measurements obtained during the two experiments with the highest peak period (respectively V1 and V3). During the experiments hydrodynamics and the bathymetric change have been measured in various ways. This paper concentrates on comparison of the XBeach results with the hydrodynamic measurements and the dune crest position derived from both wheel profiler measurements and measurements with video cameras (Van Geer et al. 2009).

\footnotetext{
${ }^{1}$ Deltares, Delft, The Netherlands

2 Department of Civil Engineering, TU Delft, Delft, Netherlands
} 


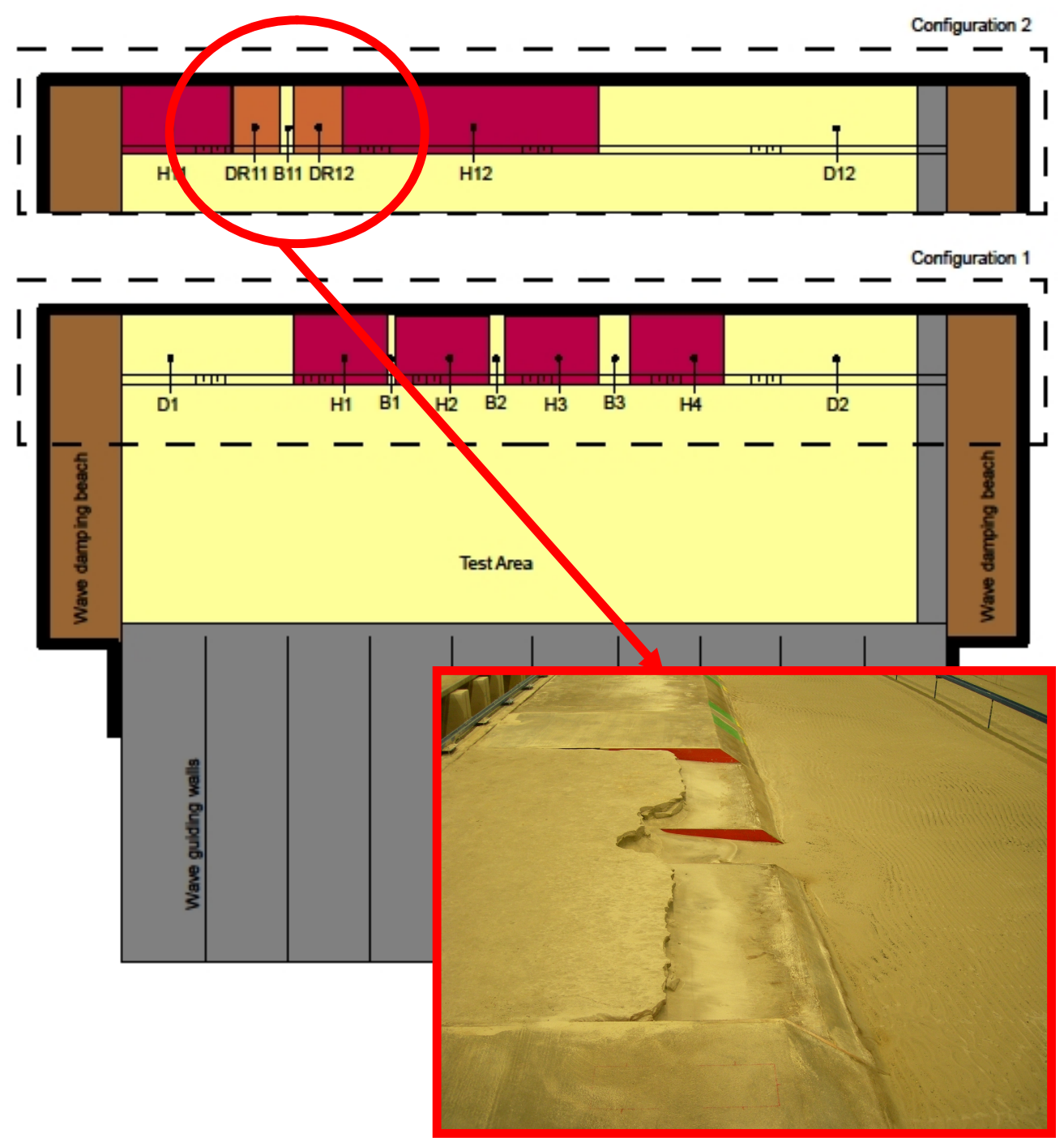

Figure 1. Visualization of the two configurations of sandy (dune) and concrete (dike) segments during the experiments in the Delta basin.

\section{XBeach model.}

The assessment of dune safety in the presence of structures requires the development of knowledge about processes governing these situations. In the SBW program this knowledge is being incorporated into the XBeach model which was initially developed for the computation of barrier island erosion under hurricane attack (e.g. Roelvink et al., 2009; McCall et al., 2010). The model solves the $2 \mathrm{D}$ horizontal conservation of mass and momentum with wave group forcing. It includes sediment transport, episodic collapse of the dune front (dune face avalanching) and the possibility to define fixed (unerodible) structures, which may or may not be covered by sediment. In principle, this allows for computation of dune erosion in the presence of fixed structures like dikes or sea-walls.

\section{EFFECT OF A STRUCTURE ON DUNE EROSION}

Additional dune erosion right next to a structure has been observed in the field during storms in the past. To account for this, the current assessment rules (Ministry of Infrastructure and the Environment, 2007) already adopt a method to quantify the additional dune erosion right next to a structure at the end of a storm. This method was first described in WL | Delft Hydraulics (1993). The method parameterizes the influence of a gradient in the bathymetry in front of the structure towards the bottom in front of the dune and computes a volume of sediment that is supposed to be transported towards the structure. However, this method has never been validated with measurements. The driving process of such sediment transport can be summarized as follows: 
1. Different bathymetry: Due to the limited supply of sediment from the structure to its foreshore compared to a dune the bottom in front of a dune elevates more than the bottom directly in front of the fixed structure.

2. Difference in wave breaking: Due to the differences in bottom elevation waves break earlier in front of the dune compared to breaking in front of the fixed structure.

3. Difference in water level setup: The difference in wave breaking causes a difference in water level setup, creating a water level gradient from the dune towards the dike.

4. Alongshore current: The water level gradient causes a mean current from the dune towards the structure.

5. Lateral sediment transport: The alongshore current transports sediment towards the structure.

6. Additional erosion of the dune front: As a consequence of this lateral sediment transport the bathymetric change in front of the dune but right next to a structure may be smaller than the change in front of an undisturbed dune section. This effect increases the wave load on the dune face and thus inducing additional erosion of the dune front. During a storm the dune front next to a structure retreats, but the structure remains at the same position. This causes a phase difference between the waves reflected on the dune and the waves that reflect on the structure. This phase difference can cause an oscillating motion around the corner of the structure stirring up extra sediment. This could increase the amount of sediment that is transported towards the structure and therefore increases the effect of the above described process.

Except for the reflection and runup of short waves XBeach includes all processes as described above. Model simulations on a schematic case with one abrupt transition between a dune and a fixed structure illustrates the described mechanism. Figure 2 illustrates the differences in the sedimentationerosion pattern in front of a dune (left) adjacent to a fixed structure (right) as computed by XBeach. According to XBeach this results in higher waves in front of the dike (Figure 3) and an increased water level in front of the dune (Figure 4). The water level gradient drives a current towards the fixed structure that increases locally near the transition between the dune and structure (see also Figure 5). This confirms the hypothesized mechanism that drives sediment transport from a dune towards a fixed structure during a storm with normally incident waves.

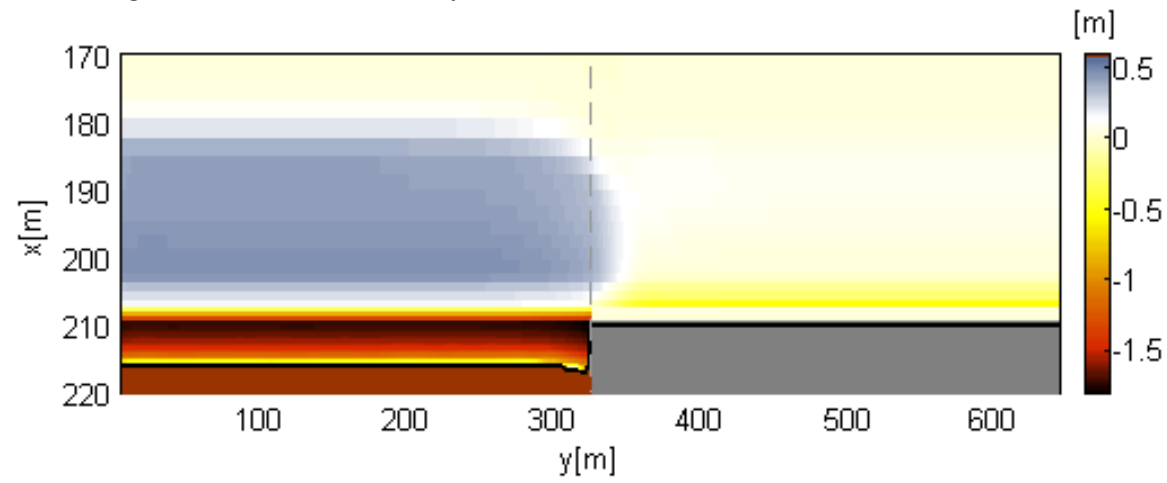

Figure 2. Spatial view of the sedimentation-erosion pattern of a dune-dike system as computed by XBeach with normally incident waves. Dunes are brown, dikes are gray and the retreat line is black. The sea is at the top and the coastline at the bottom.

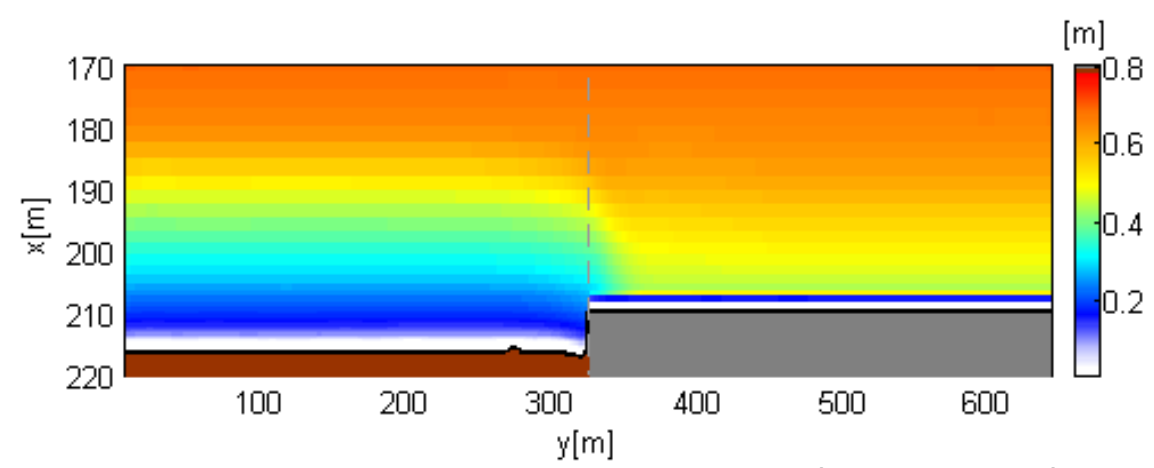

Figure 3. Spatial view of the mean wave height pattern of the short waves (normally incident) as computed by XBeach. 


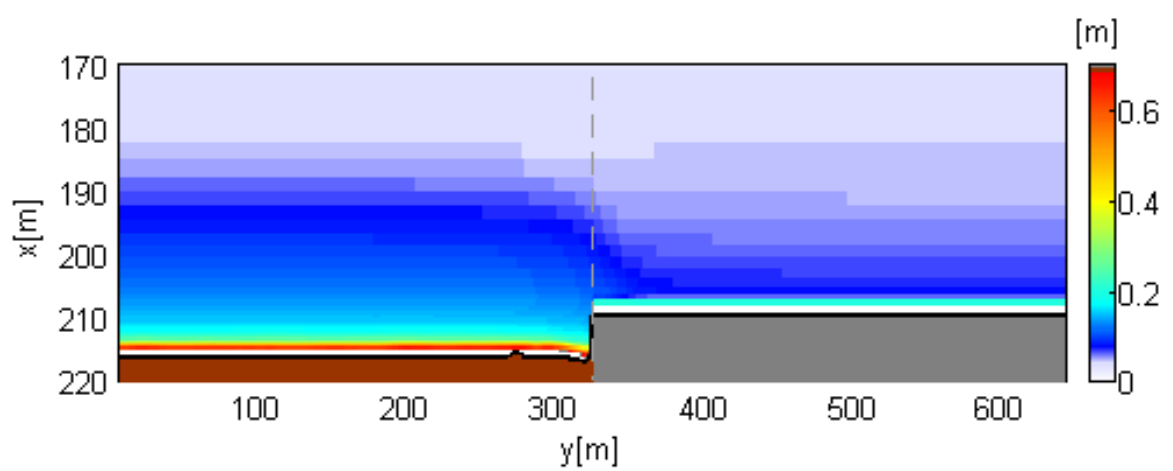

Figure 4. Spatial view of the mean still water level (including the wave-induced water level setup) as computed by XBeach with normally incident waves.

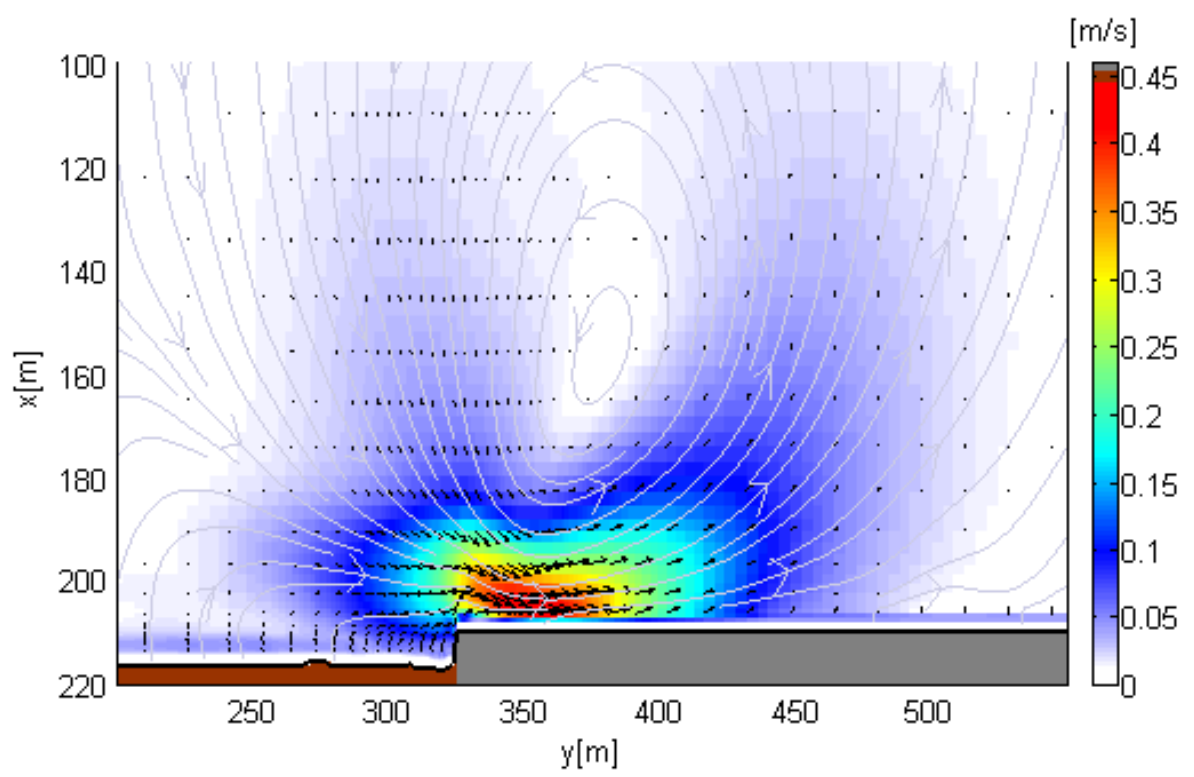

Figure 5 Spatial view of the mean velocity field in front of the dune-dike system under normally incident waves as computed by XBeach.

\section{MODEL - DATA COMPARISON}

An XBeach model was set up to represent the experimental setup, including side wall boundary conditions and absorbing-generating wave boundary conditions at the offshore boundary. The model described the concrete elements by means of unerodible layers. Simulation results show that the essential dune set back processes are captured and that the measurements at most locations are approximated quite well. This section describes the comparison with the various measurements.

\section{Hydrodynamics}

During the experiments hydrodynamics were measured along a cross-shore section of the dune profile. Figure 6 shows a comparison between the measured and computed wave height $\left(H_{m 0}\right)$ along this cross-shore transect. Measurements and calculation results are in good agreement.

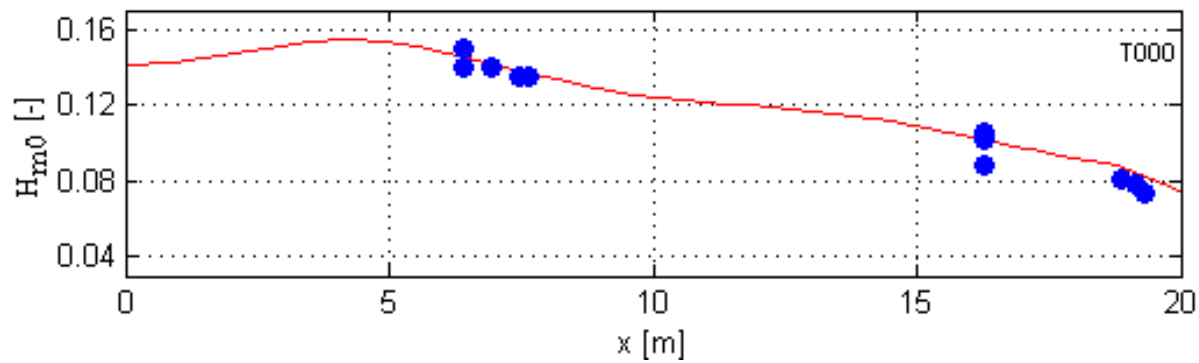

Figure 6. Comparison of the wave height measurements (blue) and the XBeach prediction (red) along a crossshore section. The wave maker boundary is to the left and the shoreline to the right. 


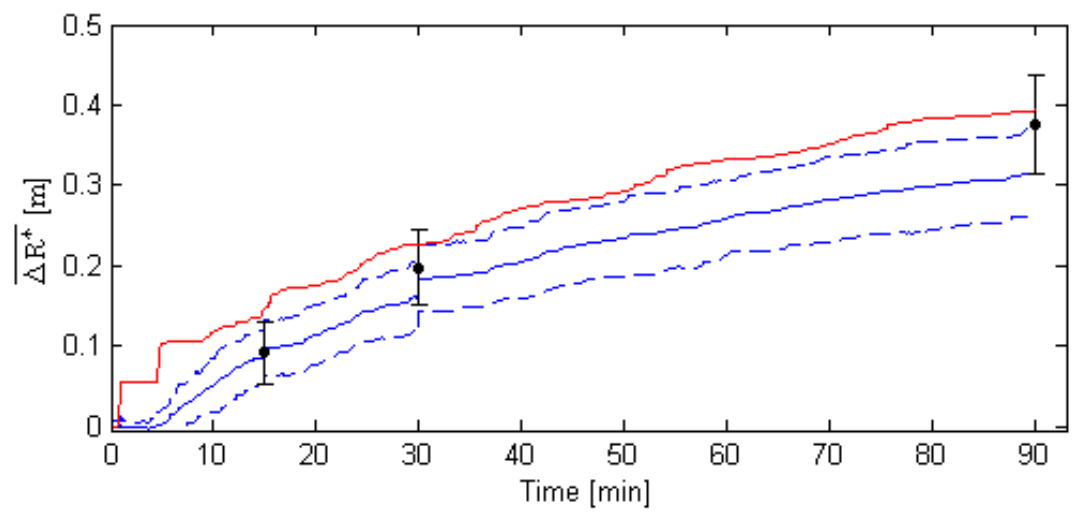

Figure 7. Mean dune crest retreat (relative to the original position) of the dune sections during the experiment with the first configuration. Blue lines denote the dune crest development retrieved from video measurements and its standard deviation, black dots denote the dune crest development derived from cross-shore profile measurements and the red line represents the dune crest development as computed by XBeach.

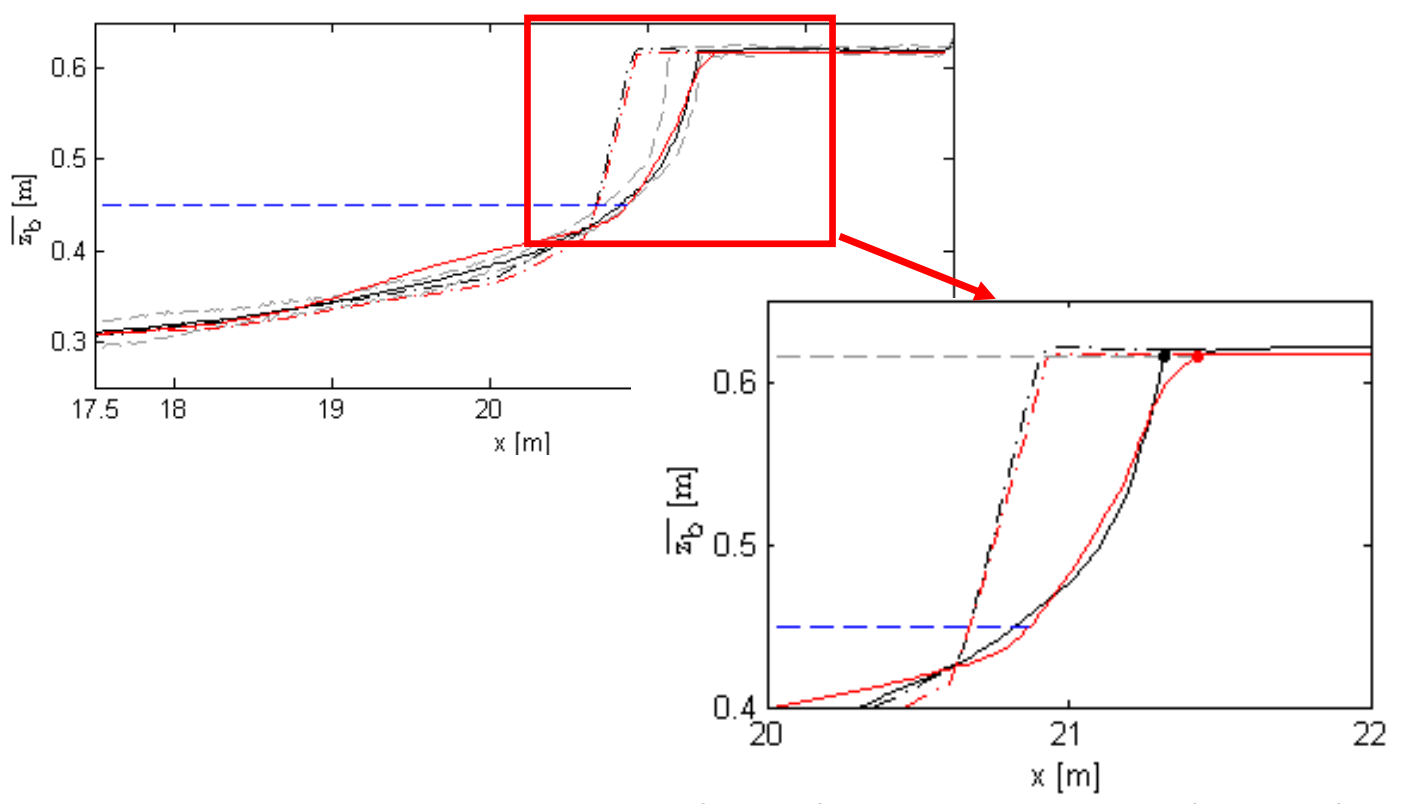

Figure 8. Mean initial and final bottom elevation of XBeach (red lines) and profile measurements (black lines). The blue line represents the maximum storm surge level and the minimum and maximum measured elevation is represented by grey lines.

\section{Dune crest retreat of unprotected dune section}

The crest of the unprotected dune stretch during the experiments showed some variation. This could be caused by a slight alongshore variation of the waves during the experiments, which cannot be derived from the measurements since hydrodynamics were measured primarily in a cross-shore transect. XBeach results do not show an alongshore variation since the wave forcing in the model was alongshore uniform and the model responded as expected. To be able to compare the computed and measured dune crest position in time therefore the XBeach calculation results were compared with the mean and standard deviation of the dune crest position in time along the unprotected dune section (Figure 7). The computed dune crest position seems to slightly overestimate the measured dune crest position. However when looking at the computed and measured cross-shore profiles (Figure 8) it becomes clear that it is just the very upper part of the dune front that gets eroded too much by XBeach. The remaining part of the dune front computed by XBeach approaches the measured bathymetry very well.

\section{Dune crest retreat at a transition between a dune and a dike}

At the transition between the unprotected dune and the concrete (dike) structure differences between the measured and computed dune crest position are clearly visible. Figure 9 shows a small 
amount of additional erosion right next to the structure in the simulation results. However, this underestimates the measured additional retreat of the dune crest. Primarily the alongshore distance over which the structure has an influence was much larger during the experiments than what was computed by XBeach. The lack of short wave reflection in the XBeach calculations that should cause increased alongshore sediment transport could explain part of this difference. Furthermore the resolution of the grid that was needed during the XBeach calculation to keep acceptable run times maybe too coarse to accurately describe the processes at the transition.

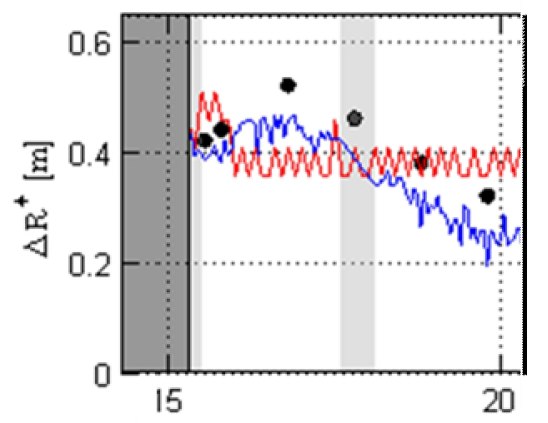

Figure 9. Spatial view of computed and measured dune crest retreat distance at the unprotected dune section in the second configuration at the end of the experiment. Blue lines represent the dune crest derived from video, the black dots visualize the dune crest measured with a wheel profiler and the red line the simulation results.

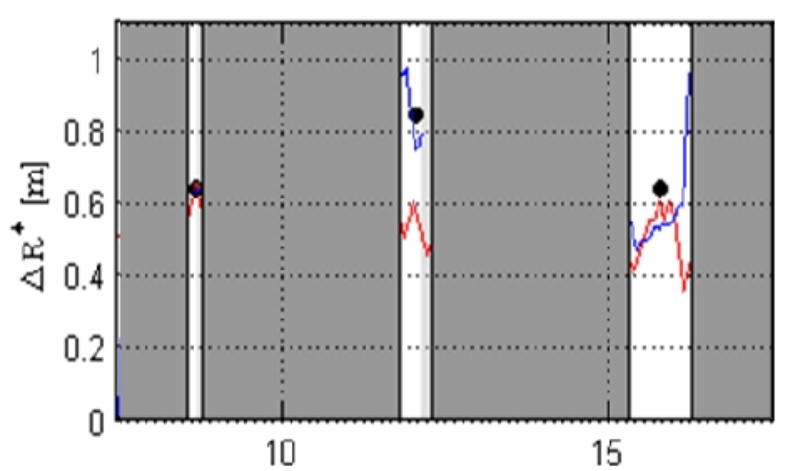

Figure 10. Spatial view comparison of the computed and measured dune crest retreat in the three breaches at the end of the experiment. Blue lines represent the dune crest derived from video, the black dots visualize the dune crest measured with a wheel profiler and the red line the simulation results.

\section{Dune crest retreat at the breaches}

Computed erosion of the dune front inside the breaches (Figure 10) is in good agreement with the measurements at the two outer breaches. In the middle breach the calculation underestimates the measured dune crest retreat. During the experiments the middle breach suffered from highly threedimensional erosion patterns. Instead of an episodic collapse of the dune front, the dune crest leaned over a large percentage of the time causing three dimensional flow patterns that cannot be resolved by XBeach. Furthermore during the experiments short waves sometimes slightly overtopped the structure leading to small streams in the middle breach of bits of water flowing back to the shoreline. This also eroded sediment of the dune in a manner that is not accounted for in XBeach.

\section{Dune crest retreat at the dune foot revetment}

Also in the breach of the dune foot revetment (Figure 11) calculation results are similar to the measured dune crest position at the end of the experiments. Above the revetment however XBeach clearly underestimates the amount of dune erosion. The simulated long waves were only able to erode some of the sediment above the revetment, since most of the waves did not overtop the revetment in the calculation. In the experiments overtopping of the revetment happened frequently, causing more erosion above the revetment. Van Thiel de Vries (2012, this volume) describes the same problem with 1D simulations of erosion of a dune that was protected with a dune foot revetment. He also describes a solution to that problem by including the parameterized effect of short wave run-up on the slope of the 
revetment. A two dimensional elaboration of this solution could bring these calculation results and measurements closer together.

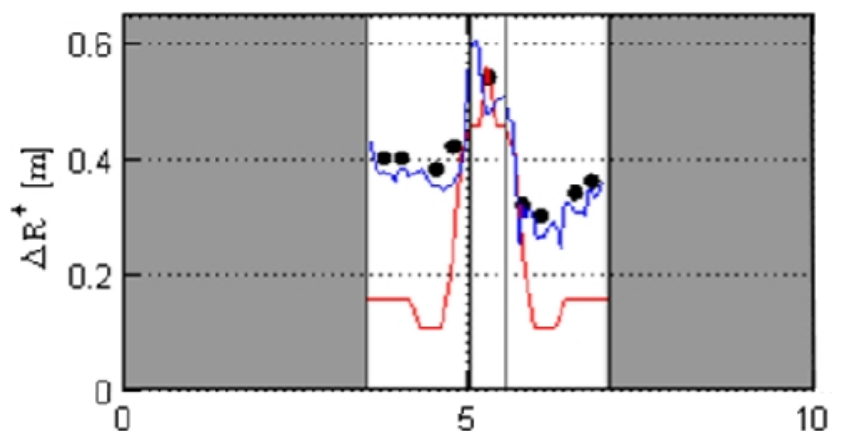

Figure 11. Plan view comparison of computed and measured dune crest retreat at the location of the dune foot revetment at the end of the experiment. Blue lines represent the dune crest derived from video and the black dots visualize the dune crest measured with a wheel profiler.

\section{APPLICATION TO OBLIQUELY-INCIDENT WAVES}

The comparison between XBeach and the measurements shows that measured dune crest retreat was well reproduced by the XBeach model. The dominant processes seem to be modeled, but need improvement for some specific situations (modeling run-up on a dune foot revetment and predicting the right additional erosion pattern near a transition between a dune and a dike). The conceptual model with only one transition between a dune and a fixed structure is now used to further investigate the dominant processes in case of obliquely incident waves. Figure 12 shows the computed flow pattern in a case with an angle of incidence of 40 degrees directed towards the structure. Figure 13 shows the flow pattern during a calculation with the same but opposite angle of incidence. From these figures it can be seen that the model predicts a continuous flow pattern along the coast. The local acceleration near the transition that characterizes the flow pattern with normally incident waves (Figure 5) disappeared. The mean velocity is also increased by a factor 4, causing different processes to play a dominant role. In the case of oblique waves towards the dike streamlines are blocked by the structure creating a wake that causes the adjacent dune to erode less than the unprotected dune section. In case of oblique waves towards the dune section, the dune adjacent to the structure erodes much more than in the case with normally incident waves. Due to differences in the suspended sediment concentration in font of the structure and the concentration in front of the dune, sediment adjacent to the structure gets picked up and transported further down the dune section.

The results of the exploration with this conceptual model show that the influence of the angle of incidence of waves could play an important role in understanding additional erosion during a storm due to the presence of fixed structures.

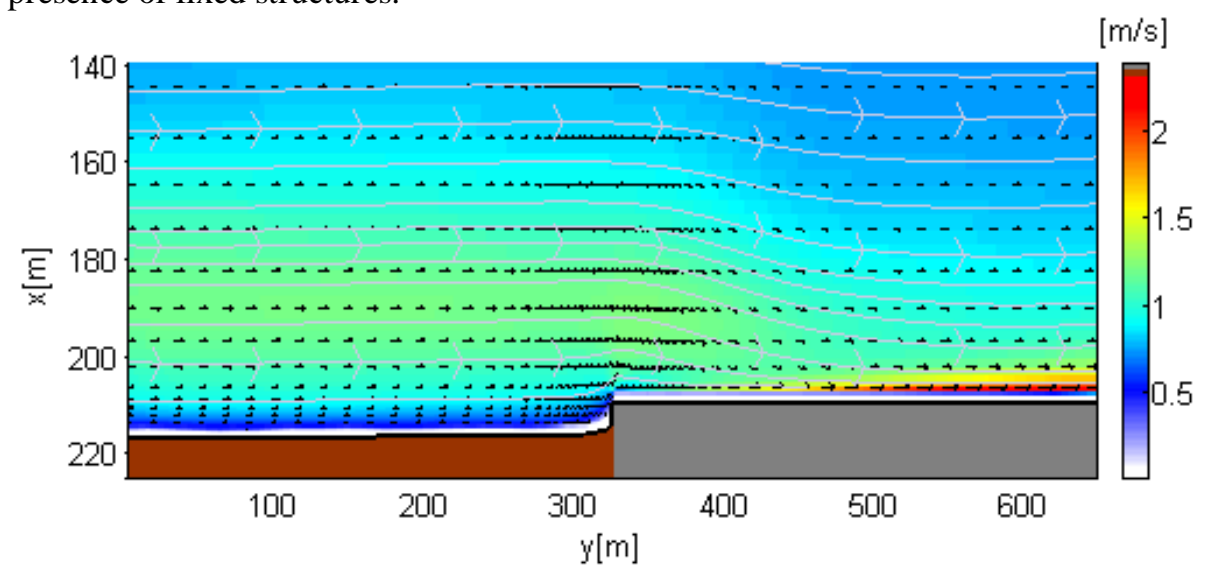

Figure 12. Mean velocity field in front of the dune-dike system for obliquely incident waves from the left: Retreat points of dune (brown) and dike (gray) cross-section are connected by the retreat line (black). 


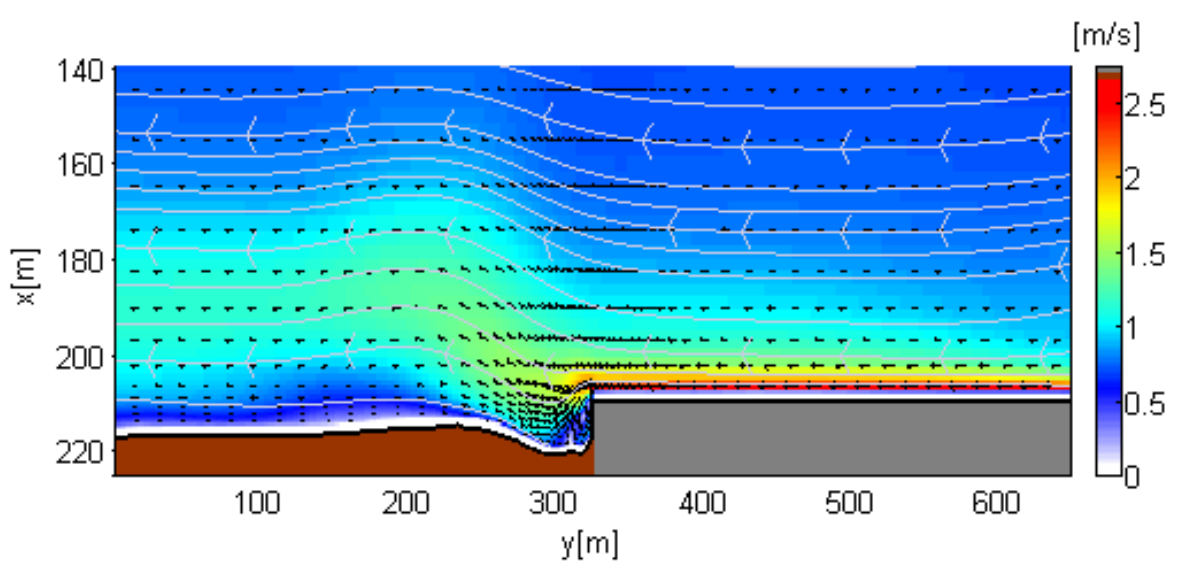

Figure 13. Mean velocity field in front of the dune-dike system for obliquely incident waves from the right: Retreat points of dune (brown) and dike (gray) cross-section are connected by the retreat line (black).

\section{DISCUSSION}

This paper describes the validation of the XBeach dune erosion model for the case of laboratorymeasured dune erosion in the presence of sea walls and revetments. In general it can be concluded that the essential dune set back processes are captured in the model and that the measurements at most locations are approximated quite well by the simulation results. Dune crest retreat inside breaches and the development of the computed dune crest retreat of the unprotected dune section in time are in agreement with the measurements. The model also computes additional erosion at a transition between a dune section and a structure. There is however a difference in the measured and computed alongshore distances over which the structure has a significant influence on the amount of dune erosion. Furthermore the erosion volume above the dune foot revetment is not well represented by the XBeach results. Further research should include the following aspects to improve the comparison between the model and measurements:

- The absence of the effect of the individual short waves in the XBeach model creates two causes for differences between the model outcomes and measurements:

- Short wave run-up on the dune foot revetment should be accounted for as it causes the sediment above the revetment to erode faster.

- Reflection of the short waves on the dune and dike structure is not accounted for. The phase difference between the reflected short waves that arises at the transition between a dune and dike section therefore is not accounted for. This phase difference can cause stirring up of sediment leading to a scour hole right at the transition and an increased amount of sediment transport.

- It is difficult to define a grid for a model that should compute the interaction between dune erosion and a fixed structure. The grid should cover a domain that is large enough to accurately represent the hydrodynamic conditions at the location of interest. At the same time it should have enough resolution at the connection between structures and sandy parts to accurately represent the morphological changes. Run-times easily get out of hand while decreasing the grid size enough to achieve the latter.

Numerical model investigations with a conceptual model that included only one transition between a dune and a fixed structure showed that the angle of incidence of the incoming waves could play an important role in the dominant flow pattern. With normally incident waves the hypothesis of differences in wave breaking as a driving force for lateral sediment exchange seems to be confirmed. Increasing the angle of incidence also changes the dominance of the various processes up till the point that the alongshore current induced by radiation stresses completely determines the flow pattern. In the case with an angle of incidence of 40 degrees to shore normal no local flow pattern at the transition can be identified anymore. Also the flow can reach higher velocities due to obliquely incident waves leading to a larger effect on the amount of additional dune erosion adjacent to the structure. Therefore the angle of incidence of the incoming waves should also be considered in future research on the effect of fixed structures on dune erosion. 


\section{REFERENCES}

Boers M.B., Van Geer P.F.C., Van Gent M.A. (2011): Dike and dune revetment impact on dune erosion, Proc. Coastal Sediments 2011.

McCall R.T., Van Thiel de Vries J.S.M., Plant N.G., Van Dongeren A.R., Roelvink J.A., Thompson D.M., Reniers A.J.H.M. (2009): Two-dimensional time dependent hurricane overwash and erosion modelling at Santa Rosa Island, Coastal Engineering, Vol. 57, 7, pp. 668-683, DOI: 10.1016/j.coastaleng.2010.02.006.

Ministry of Infrastructure and the environment (2007), VTV2006: Voorschrift Toetsen op Veiligheid Primaire Waterkeringen (Safety Assessment Rules for the Dutch Primary Sea Defenses) (In Dutch).

Roelvink J.A., Reniers A.J.H.M., Van Dongeren A.R., Van Thiel de Vries J.S.M., McCall R.T., Lescinski J. (2009): Modeling storm impacts on beaches, dunes and barrier islands, Coastal Engineering, doi: DOI: 10.1016/j.coastaleng.2009.08.006

Van Geer P.F.C., Boers M.B., and van Gent M.A. (2009): Measurements on the interaction between dunes and dikes during extreme storms, Proc. Coastal Dynamics, Tokyo, Japan.

Van Thiel de Vries J.S.M. (2012): Dune erosion above revetments, Proc. ICCE 2012.

WL | Delft Hydraulics (1993): Effect bebouwing op de mate van duinafslag (Effect of structures on the amount of dune erosion). Project number: H1696 (In Dutch). 